\title{
Risk factors for bleeding after gastric endoscopic submucosal dissection: a systematic review and meta-analysis \\ Diogo Libânio, MD, ${ }^{1}$ Mariana Nuno Costa, MD,${ }^{2}$ Pedro Pimentel-Nunes, MD, PhD, ${ }^{1,3}$ Mário Dinis-Ribeiro, MD, PhD $^{1,3}$
}

Porto, Lisbon, Portugal

\begin{abstract}
Background and Aims: Postprocedural bleeding (PPB) is the most common adverse event associated with endoscopic resection. Several studies have tried to identify risk factors for PPB after gastric EMR and endoscopic submucosal dissection (ESD), with controversial results. This systematic review and meta-analysis aimed to identify significant risk factors for PPB after gastric EMR and ESD.
\end{abstract}

Methods: Three online databases were searched. Pooled odds ratio (OR) was computed for each risk factor using a random-effects model, and heterogeneity was assessed by Cochran's Q test and $\mathrm{I}^{2}$.

Results: Seventy-four articles were included. Pooled PPB rate was 5.1\% (95\% confidence interval, 4.5\%-5.7\%), which did not vary according to different study designs. Male sex (OR, 1.25), cardiopathy (OR, 1.54), antithrombotic drugs (OR, 1.63), cirrhosis (OR, 1.76), chronic kidney disease (OR, 3.38), tumor size > $20 \mathrm{~mm}(\mathrm{OR}, 2.70)$, resected specimen size $>30 \mathrm{~mm}(\mathrm{OR}, 2.85)$, localization in the lesser curvature (OR, 1.74), flat/depressed morphology (OR, 1.43), carcinoma histology (OR, 1.46), and ulceration (OR, 1.64) were identified as significant risk factors for PPB, whereas age, hypertension, submucosal invasion, fibrosis, and localization (upper, middle, or lower third) were not. Procedure duration $>60$ minutes (OR, 2.05) and the use of histamine-2 receptor antagonists instead of proton pump inhibitors (OR, 2.13) were the procedural factors associated with PPB, whereas endoscopist experience and preprocedural proton pump inhibitors were not. Second-look endoscopy was not associated with decreased PPB (OR, 1.34; 95\% confidence interval, .85-2.12).

Conclusions: Risk factors for PPB were identified that can help to guide management after gastric ESD, namely adjusting further management. Second-look endoscopy is not associated with decreased PPB. (Gastrointest Endosc 2016;84:572-86.)

Endoscopic submucosal dissection (ESD) and EMR are well-established treatments for early gastric neoplasms. ${ }^{1}$ Bleeding is the most frequent adverse event associated with ESD and EMR, occurring in $7.1 \%$ to $9.4 \%$ and $7.1 \%$ to $8.6 \%$ of the procedures, respectively. ${ }^{2-4}$ Specifically, postprocedural bleeding (PPB) is reported to occur in $4.53 \%$ after ESD and $3.97 \%$ after EMR. ${ }^{2}$

Both patient and lesion characteristics, as well as medications and procedural technical features, may influence the risk of bleeding. Several studies have addressed this issue over time, aiming at identifying risk factors for PPB. However, some controversy exists, and the significant risk factors for post-EMR/ESD bleeding are yet to be identified. The identification of these risk factors is of paramount importance to estimate bleeding risk and to stratify patients, namely to guide management after ESD/ EMR. Therefore, we aimed at identifying the risk factors for PPB after EMR and ESD for early gastric neoplasms.
Abbreviations: AT, antithrombotic therapy; CI, confidence interval; ESD, endoscopic submucosal dissection; $H_{2} R A$, histamine-2 receptor antagonist; OR, odds ratio; PPB, postprocedural bleeding; PPI, proton pump inbibitor; RCT, randomized controlled trial; SLE, second-look endoscopy. DISCLOSURE: All authors disclosed no financial relationships relevant to this publication.

Copyright $\odot 2016$ by the American Society for Gastrointestinal Endoscopy 0016-5107/\$36.00

http://dx.doi.org/10.1016/j.gie.2016.06.033

\section{METHODS}

\section{Study search and selection}

Studies were identified through scanning of 3 electronic databases (MEDLINE through PubMed, Scopus, and ISI Web of Knowledge), with the last search performed on July 15, 2015. The search query for PubMed was ([gastric OR stomach] AND ["endoscopic submucosal dissection" OR "endoscopic mucosal resection"]) AND (bleeding OR 
hemorrhage). Queries for other databases were adapted from this query. Additional studies were identified by checking the list of references of all included studies and reviews on the topic.

Two independent investigators (D.L., M.N.C.) screened titles and abstracts to exclude irrelevant studies. The full text of relevant studies was then analyzed by these same authors according to the criteria below. Disagreements were solved by consensus with the intervention of a third reviewer (P.P.N.) when required. This phase was performed with Covidence online platform (www.covidence. org).

Abstracts and fully published studies were considered for inclusion with no date or language restrictions. Inclusion criteria were (1) retrospective or prospective, case-control or cohort studies and clinical trials (including randomized controlled trials [RCTs]); (2) studies evaluating patients submitted to EMR or ESD to treat gastric superficial neoplasms (dysplastic lesions or early gastric cancers); (3) studies with PPB rates reported separately from intraprocedural bleeding; and (4) studies where risk factors for PPB were analyzed. Articles were excluded if (1) PPB rates were not clearly reported; (2) fewer than 20 patients were included; (3) they were feasibility studies of innovative techniques/devices without control group; (4) they were comments, reviews, letters, or surveys; (5) they were case reports; or (6) they were animal studies.

\section{Quality evaluation and data extraction}

Data extraction and quality assessment were performed by D.L. using prespecified forms that were refined after piloting in 10 studies. Another reviewer (M.N.C.) independently checked the extracted data, and disagreements were solved by consensus. Data extraction forms included (1) author, (2) publication year, (3) setting, (4) study period, (5) study design, (6) randomization methods if applicable, (7) allocation concealment, (8) blinding, (9) type of endoscopic resection (EMR/ESD), (10) number of participants, (11) definition of PPB, (12) frequency of PPB (total and for each risk factor), (13) antacids (route, dosage, duration of therapy), (14) antithrombotic management, (15) operator (single/multiple, experienced/nonexperienced), and (16) second-look endoscopy (SLE). In the data extraction form, crude data and results of statistical analysis were recorded for each risk factor. Quality evaluation was performed using the Cochrane risk of bias tool for RCTs ${ }^{5}$ and the Newcastle-Ottawa scale for observational studies. ${ }^{6}$ Also, the quality of reporting of acid inhibition strategy and antithrombotic management was assessed.

\section{Data synthesis and statistical analysis}

Odds ratios (ORs) and 95\% confidence intervals (CIs) for each categoric risk factor and the mean or median for continuous data was registered (or calculated whenever possible). Studies providing data allowing the calculation of ORs were then included in a meta-analysis, performed by computing pooled ORs (for categoric variables) and mean differences (for continuous variables) using a random-effects model. Pooled PPB prevalence was calculated with a random-effects model with OpenMetaAnalyst. ${ }^{7}$ Meta-analysis was performed using RevMan 5.3. ${ }^{8}$ Heterogeneity was evaluated with the Cochran $Q$ test and $\mathrm{I}^{2}$. Significant heterogeneity was defined as $\mathrm{I}^{2}>40 \%$ and $P<.05$. For continuous outcomes, median and interquartile range/range were transformed into mean and standard deviation through the methods proposed by the Cochrane collaboration and Hozo et al. ${ }^{9}$ Sensitivity analysis was planned, excluding these studies and whenever significant heterogeneity was found. Subgroup analysis was planned according to study design, time of bleeding (early or delayed), and antithrombotic management. This study was conducted in accordance with the PRISMA recommendations for reporting systematic reviews and meta-analysis. ${ }^{10}$

\section{RESULTS}

\section{Characteristics of included studies and quality evaluation}

In total, 1043 studies were identified (1038 through database search and 5 through manual searching), and 74 references (71 studies) were finally included in this systematic review (Fig. 1). A summary of the included studies and quality evaluation ( 15 RCTs, 3 prospective trials, 5 prospective cohort studies, and 48 retrospective cohort and case-control studies) is shown in Table 1. Seventy-three percent of RCTs were judged to have low risk of bias, whereas observational studies had a median and mean Newcastle-Ottawa score of 7 and 7.5, respectively. Almost all studies reported that proton pump inhibitors (PPI) or histamine-2 receptor antagonists $\left(\mathrm{H}_{2} \mathrm{RAs}\right)$ were administered in the periprocedural period, although route, dosage, frequency of administration, and duration of treatment were not accurately reported in $42 \%$ of the studies. Moreover, the management of antithrombotics was not clearly reported in 24 studies (32\%).

\section{PPB definition and rate}

The most common definition of PPB was clinical evidence of bleeding (hematemesis/melena) or hemoglobin drop $\geq 2 \mathrm{~g} / \mathrm{dL}$ requiring endoscopic hemostasis. Definitions of early and delayed bleeding were heterogeneous among studies, with some studies defining early bleeding as those occurring in the first 24 hours, whereas others considered early bleeding those that occurred in the first 48 hours or in the first 5 days after ESD

PPB rates ranged from $.6 \%{ }^{11}$ to $26.9 \%,{ }^{12}$ and the pooled PPB rate was 5.1\% (95\% CI, 4.5\%-5.7\%), with significant heterogeneity across studies $\left(\mathrm{I}^{2}=84.46, P<.001\right)$. However, PPB rates were not significantly different according to study design $5.9 \%$ in RCTs, $6.1 \%$ in prospective studies, and $4.9 \%$ in retrospective studies; $\mathrm{I}^{2}>80 \%$ ). 
1043 references identified

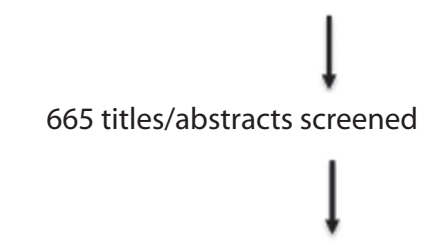

284 articles assessed for full-text eligibility

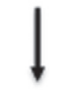

74 articles included (71 studies)

- 70 full-published papers

- 4 abstracts

62 studies included in meta-analysis

Figure 1. Flowchart of included studies.

The time of bleeding was determined in 28 studies. Definitions of early and delayed bleeding were also heterogeneous across studies. Most bleeding episodes (213/374; $56.9 \%$ ) occurred more than 24 hours after ESD. Among the 4 studies classifying early PPB as bleeding $<48$ hours after ESD, 92 of 135 PPB events (68.2\%) occurred in this time period. As stated below, among those studies reporting delayed bleeding ( $>48$ hours after ESD) only, upper localization was associated with a higher bleeding risk.

\section{Risk factors for PPB}

All included studies explored risk factors for PPB after ESD, whereas risk factors for PPB after EMR were evaluated in 3 studies. Most studies (54\%) evaluated multiple risk factors (case-control design), whereas $46 \%$ focused on single risk factors (eg, age, size, premedication with PPIs). Significant risk factors found in the meta-analysis are summarized in Figure 2, and the effect estimates for each risk factor are shown in Tables 2, 3, and 4.

Patient factors. Age was not identified as a risk factor in most studies, ${ }^{13-33}$ with only 1 study reporting that younger patients may be at higher risk for PPB. ${ }^{34}$ Furthermore, 10 studies found no significant differences in elderly patients, ${ }^{19,25,30,35-41}$ although 1 study identified age $>80$ years as an independent risk factor for PPB. ${ }^{42}$ PPB rates were similar between genders in most studies, ${ }^{13-18,20-23,25-34,36,39,42-44}$ with only 1 study reporting an association male sex associated with PPB. ${ }^{24}$

Arterial hypertension was not identified as a risk factor in most studies, ${ }^{13-15,17,18,20-24,28-31,33,42,43,45}$ although 2 studies reported significantly higher PPB rates in hypertensive patients. ${ }^{16,36}$ However, the adjusted OR was .67 in the latter study. ${ }^{36}$ Similarly, diabetes mellitus was not identified as a significant risk factor in any study. $13-18,20-24,28-31,33,34,36,42,44,45$

Cardiopathy (ischemic heart disease in most studies), ${ }^{10,13,17,20,23,28,29,31,34,36,42,44,45}$ cerebrovascular disease, $^{15,21-23,28,36,42,45}$ and cirrhosis ${ }^{14,17,18,22,24,26,28,29,34,36,43,45}$ were not identified as risk factors for PPB in most studies. Chronic kidney disease was not identified as a risk factor in some studies despite a trend to higher bleeding. ${ }^{14,17,22,28,30,34,42}$ However, 3 studies found significantly increased PPB rates in patients with chronic kidney disease $^{45}$ and undergoing dialysis. ${ }^{18,46}$

Comorbidities $^{28,45}$ and American Society of Anesthesiologists Physical Status Classification System status ${ }^{47}$ were not identified to be associated with PPB, although 1 study found increased PPB risk in patients with significant cOmorbidities. ${ }^{25}$ Other clinical factors were analyzed in a few studies. Helicobacter pylori infection, ${ }^{13,14,22}$ body mass index, ${ }^{22,29,36}$ hyperlipidemia, ${ }^{24,29,31,34,42}$ hyperuricemia, ${ }^{36}$ pulmonary disease, ${ }^{34}$ history of peptic ulcer, ${ }^{31}$ hemoglobin level, ${ }^{22}$ prothrombin, and activated partial thromboplastin time ${ }^{22,25}$ were not found to be associated with PPB. Thrombocytopenia was associated with PPB in 1 study, ${ }^{43}$ although 2 studies did not find differences in PPB rates. ${ }^{16,22}$

Finally, previous gastric surgery (ESD in gastric remnant or gastric tube) was not associated with increased PPB. ${ }^{22,48,49}$ However, 1 study found a higher PPB rate when the anastomotic site was involved. ${ }^{48}$

After meta-analysis, male sex, cardiopathy, cirrhosis, and chronic kidney disease were significantly associated with PPB. Among patients with chronic kidney disease, dialysis was associated with an increased PPB risk (Table 2). Again, age, hypertension, diabetes mellitus, and cerebrovascular disease were not found to influence PPB. 
TABLE 1. General characteristics of included studies

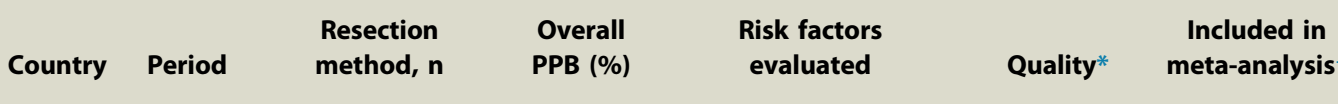

RCTs

\begin{tabular}{|c|c|c|c|c|c|c|c|}
\hline Ono S, $2009^{11}$ & Japan & $04-07$ & ESD, 155 & .6 & Single (pre-PPI) & Low risk & Yes \\
\hline Lee $\mathrm{BI}, 2011^{69}$ & Korea & 08-09 & ESD, 52 & 1.9 & Single (closure) & Unclear risk & No \\
\hline Watanabe $Y, 2006^{79}$ & Japan & $02-03$ & ESD, 98 & 3.1 & Single (pre-PPI) & High risk & Yes \\
\hline Kim S, $2014^{74}$ & Korea & $11-12$ & ESD, 120 & 4.2 & Single (early diet) & Low risk & No \\
\hline Mochizuki S, $2015^{84}$ & Japan & $12-13$ & ESD, 262 & 4.6 & Multiple & Low risk & Yes \\
\hline Baeg MK, $2014^{77}$ & Korea & NR & ESD, 98 & 6.1 & Single (pre-PPI) & Unclear risk & Yes \\
\hline Uedo $N, 2006^{81, \uparrow}$ & Japan & 05 & ESD, 105 & 6.7 & Single (PPI vs $\mathrm{H}_{2} \mathrm{RA}$ ) & Unclear risk & Yes \\
\hline Ahn JY, $2015^{62}$ & Korea & 08-09 & ESD, 79 & 7.6 & Single (ecabet sodium) & Low risk & Yes \\
\hline Jeong $H K, 2007^{60}$ & Korea & $05-06$ & ESD, 164 & 7.9 & Multiple & Low risk & Yes \\
\hline \multicolumn{8}{|l|}{ Prospective studies } \\
\hline Hikichi T, $2014^{78}$ & Japan & 07-08 & ESD, 55 & 1.8 & Single (pre-PPI) & 8 & Yes \\
\hline Lim SM, $2013^{83}$ & Korea & 08-11 & ESD, 1461 & 4.4 & Single (fatigue) & 9 & No \\
\hline Park $\mathrm{CH}, 2015^{30}$ & Korea & $11-12$ & ESD, 459 & 5.4 & Multiple & 9 & Yes \\
\hline Kikuchi $D, 2013^{73}$ & Japan & $08-10$ & ESD, 89 & 5.6 & Single (EUS findings) & 7 & No \\
\hline Na S, $2015^{28}$ & Korea & $11-12$ & ESD, 706 & 5.8 & Multiple & 7 & Yes \\
\hline Nishide N, $2012^{48}$ & Japan & 02-09 & ESD, 1541 & 10.6 & Single (remnant) & 7 & Yes \\
\hline Tsuji Y, 2015 & Japan & $13-14$ & ESD, 86 & 13.9 & Single (PGA sheets) & 9 & No \\
\hline Ono $S, 2015^{12}$ & Japan & $12-14$ & ESD, 26 & 26.9 & Multiple & 8 & Yes \\
\hline Isomoto $\mathrm{H}, 2010^{19}$ & Japan & 01-07 & ESD, 713 & 2.5 & Single (age) & 7 & Yes \\
\hline Yamaguchi N, $2009^{63}$ & Japan & 01-07 & ESD, 713 & 2.5 & Single (indication) & 7 & Yes \\
\hline Kim ER, $2015^{20}$ & Korea & $09-10$ & ESD, 550 & 2.5 & Multiple & 8 & Yes \\
\hline Higashiyama M, $2011^{18}$ & Japan & 05-09 & ESD, 924 & 3.0 & Multiple & 9 & Yes \\
\hline Akasaka T, $2011^{76}$ & Japan & 03-08 & ESD, 1188 & 3.1 & Multiple & 4 & No \\
\hline Mukai $S, 2013^{70}$ & Japan & $07-12$ & ESD, 234 & 3.4 & Single (clipping) & 7 & No \\
\hline Sugimoto $T, 2012^{39}$ & Japan & $02-08$ & ESD, 485 & 3.7 & Multiple & 9 & Yes \\
\hline Asakuma Y, 2011 ${ }^{57, \uparrow}$ & Japan & $02-07$ & ESD, 386 & 3.9 & Multiple & 6 & No \\
\hline Goto $0,2009^{68}$ & Japan & $04-07$ & ESD, 119 & 4.0 & Snaring & 8 & No \\
\hline Kim SE, $2013^{23}$ & Korea & 06-11 & ESD, 396 & 4.0 & Multiple & 7 & Yes \\
\hline Cho SJ, $2012^{15}$ & Korea & $99-03$ & ESD, 514 & 4.1 & Multiple & 9 & Yes \\
\hline Kawai N, $2007^{52, \dagger}$ and $2012^{53}$ & Japan & $03-05$ & ESD, 552 & 4.2 & Single (antithrombotics) & 6 & Yes \\
\hline Okada K, $2011^{29}$ & Japan & $05-08$ & ESD, 582 & 4.3 & Multiple & 9 & Yes \\
\hline
\end{tabular}




\begin{tabular}{|c|c|c|c|c|c|c|c|}
\hline Takeuchi T, $2013^{54}$ & Japan & $02-12$ & ESD, 833 & 4.3 & Multiple & 7 & Yes \\
\hline Sanomura $Y, 2014^{50}$ & Japan & 05-12 & ESD, 94 & 4.3 & Single (antithrombotics) & 7 & Yes \\
\hline Kosaka T, $2014^{65}$ & Japan & $02-07$ & ESD, 438 & 4.3 & Single (indication) & 7 & Yes \\
\hline Man-i M, $2013^{47}$ & Japan & $07-10$ & ESD, 527 & 4.4 & Single (ASA) & 7 & Yes \\
\hline Hirasaki S, $2007^{56}$ & Japan & $02-06$ & ESD, 112 & 4.5 & Single (size) & 7 & Yes \\
\hline Kim BJ, $2010^{45}$ & Korea & $03-06$ & ESD, 337 & 4.7 & Single (comorbidity) & 7 & Yes \\
\hline Matsumura T, $2014^{26}$ & Japan & $05-14$ & ESD, 425 & 4.7 & Multiple & 7 & Yes \\
\hline Chinda D, $2015^{35}$ & Japan & 04-09 & ESD, 307 & 5.2 & Single (age) & 7 & Yes \\
\hline Yoshio T, $2013^{40}$ & Japan & $03-11$ & ESD, 1250 & 5.3 & Single (antithrombotics) & 6 & No \\
\hline Koh R, $2013^{24}$ & Japan & $00-10$ & ESD, 1166 & 5.3 & Multiple & 9 & Yes \\
\hline Jeong JY, $2012^{67}$ & Korea & $06-11$ & ESD, 167 & 5.4 & Single (fibrosis) & 7 & Yes \\
\hline Choi CW, $2014^{13}$ & Korea & $08-12$ & ESD, 616 & 5.6 & Multiple & 9 & Yes \\
\hline Onochi K, 2010 $0^{51} \ddagger$ & Japan & 03-09 & ESD, 468 & 5.6 & Single (antithrombotics) & 6 & Yes \\
\hline Goto $0,2010^{17}$ & Japan & 03-08 & ESD, 454 & 5.7 & Multiple & 7 & Yes \\
\hline Takizawa T, $2008^{31}$ & Japan & $00-04$ & ESD, 1083 & 5.8 & Multiple & 8 & Yes \\
\hline Tusji $Y, 2010^{33}$ & Japan & 07-09 & ESD, 398 & 5.8 & Multiple & 9 & Yes \\
\hline Oka S, $2006^{66}$ & Japan & $90-04$ & ESD, 195; EMR, 825 & $11.3 / 7.0$ & Single (ulceration) & 6 & No \\
\hline Mukai S, $2012^{27}$ & Japan & $07-10$ & ESD, 161 & 13 & Multiple & 9 & Yes \\
\hline Numata $N, 2013^{46}$ & Japan & $04-12$ & ESD, 79 & 13.9 & Single (dialysis) & 7 & Yes \\
\hline Chung I-K, $2009^{58}$ & Korea & $06-07$ & ESD, 1000 & 15.6 & Multiple & 9 & Yes \\
\hline
\end{tabular}

NR, Not reported; $P G A$, polyglycolic acid sheets; $A S A$, American Society of Anesthesiologists Physical Status Classification System; $R C T$, randomized controlled trial; PPB, postprocedural bleeding; $E S D$, endoscopic submucosal dissection.

*Quality evaluation using Cochrane risk of bias table for randomized controlled trials and Newcastle-Ottawa scale for observational studies.

$\dagger$ TRisk factors evaluated in only 1 study were not included in meta-analysis as well as studies not providing data, allowing calculation of odds ratio.

$\ddagger$ Abstract.

Medications. Seventeen studies $32,39,48,49,55,57,58,63-$ $68,70,71,76,82$ did not report whether patients with antithrombotic therapy (AT) were included, and 9 studies $^{11,59,60,62,73,74,77,79,81}$ excluded patients on AT (pooled PPB rates, 5.0\% and 5.4\%). Seven studies $^{16,27,35,52,53,56,75}$ did not clearly report AT management (pooled PPB, 3.6\%), whereas this was adequately reported in the remaining studies.

AT was not identified as a risk factor in 17 studies. $^{13,14,16-}$ 18,20-23,27-31,36,42,43 However, meta-analysis showed that PPB was significantly associated with AT use (Fig. 3). In subgroup analysis PPB risk was not significantly increased if
AT were withheld 1 week before and after ESD, whereas AT resumption immediately after ESD was significantly associated with PPB.

Regarding low-dose aspirin, a study found that PPB was more frequent in continuous aspirin users than in those who never used or discontinued aspirin therapy, with a trend to later bleeding. ${ }^{15}$ On the other hand, 2 studies found no significant increase in PPB rates in patients submitted to ESD under low-dose aspirin despite a tendency to higher bleeding. ${ }^{25,26,50}$ Other studies found that PPB was associated with the use of anticoagulants ${ }^{51}$ and double $\mathrm{AT}^{52,53}$ but not with antiplatelet monotherapy. On 


\section{Risk factors for post-ESD bleeding}

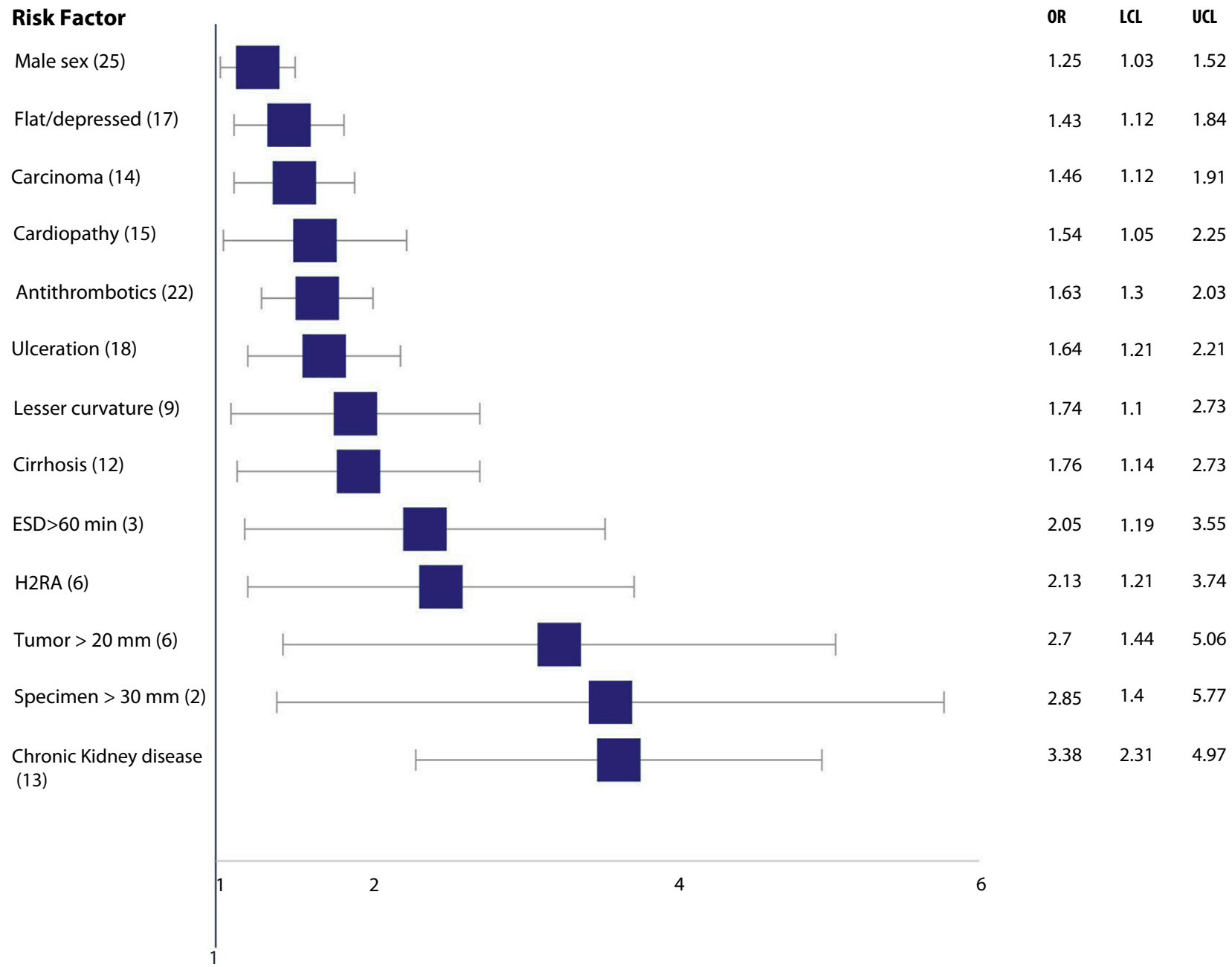

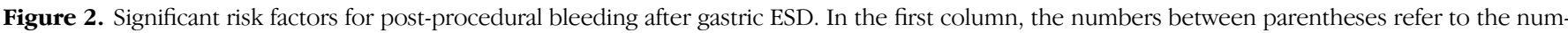
ber of studies used in the calculation of odds ratio. $L C L$, lower confidence limit (95\%); UCL, upper confidence limit (95\%).

the other hand, thienopyridines were associated with higher PPB risk even with discontinuation for 5 to 8 days before and resumption at a median of 3 days after ESD. ${ }^{12}$

Heparin replacement was not identified as a significant risk factor in 1 study, ${ }^{43}$ although an opposite result was found in another study. ${ }^{40}$ Gastroprotective agents were associated with lower PPB in patients undergoing AT in 1 study. ${ }^{54}$ Corticosteroid use was not identified as a risk factor for PPB. ${ }^{16,24,43}$

Lesion characteristics. Tumor size and resected specimen size were evaluated as risk factors in several studies. Lesion sizes $>10 \mathrm{~mm}^{55}$ and $>20 \mathrm{~mm}^{43,56}$ were not found to increase PPB in some studies, whereas lesion sizes $>20 \mathrm{~mm},{ }^{20,22,39,57-59}>30 \mathrm{~mm},{ }^{39}$ and $>40 \mathrm{~mm}^{58}$ were found to be associated with higher PPB risk in others. Regarding specimen size, the larger the ulcer, the higher the risk, with an artificial ulcer $>30 \mathrm{~mm},{ }^{36} \geq 34 \mathrm{~mm},{ }^{60}$ $>40 \mathrm{~mm}^{23-26,30,61}$ and $>50 \mathrm{~mm}^{36,43}$ identified as risk fac- tors for PPB in diverse studies. When the studies evaluated the mean sizes of tumors and resected specimens between those with PPB and those without, the results were conflicting, with some reporting significant differences between tumor $^{22,26,34,42}$ and specimen ${ }^{21,23,24,29,34,42}$ sizes and others not finding significant differences between the 2 groups. ${ }^{13,14,16-18,20,27,28,31-33,51}$

In addition, results concerning whether tumor location impacts PPB were controversial. Four studies reported that tumors located in the lower third ${ }^{33,34,36,57}$ and in the middle/lower third ${ }^{27,31,37,38}$ of the stomach had significantly higher bleeding rates, whereas the upper location of the stomach was found to be a significant risk factor in other studies. ${ }^{30,58}$ However, several studies reported no significant differences in PPB according to tumor location. ${ }^{14-18,20-29,32,39,42,43,51,55,61}$ Horizontal localization (anterior or posterior wall; lesser or greater curvature) was not found to influence PPB in individual studies. ${ }^{15-17,20-24,27,29}$ Regarding the relationship between 


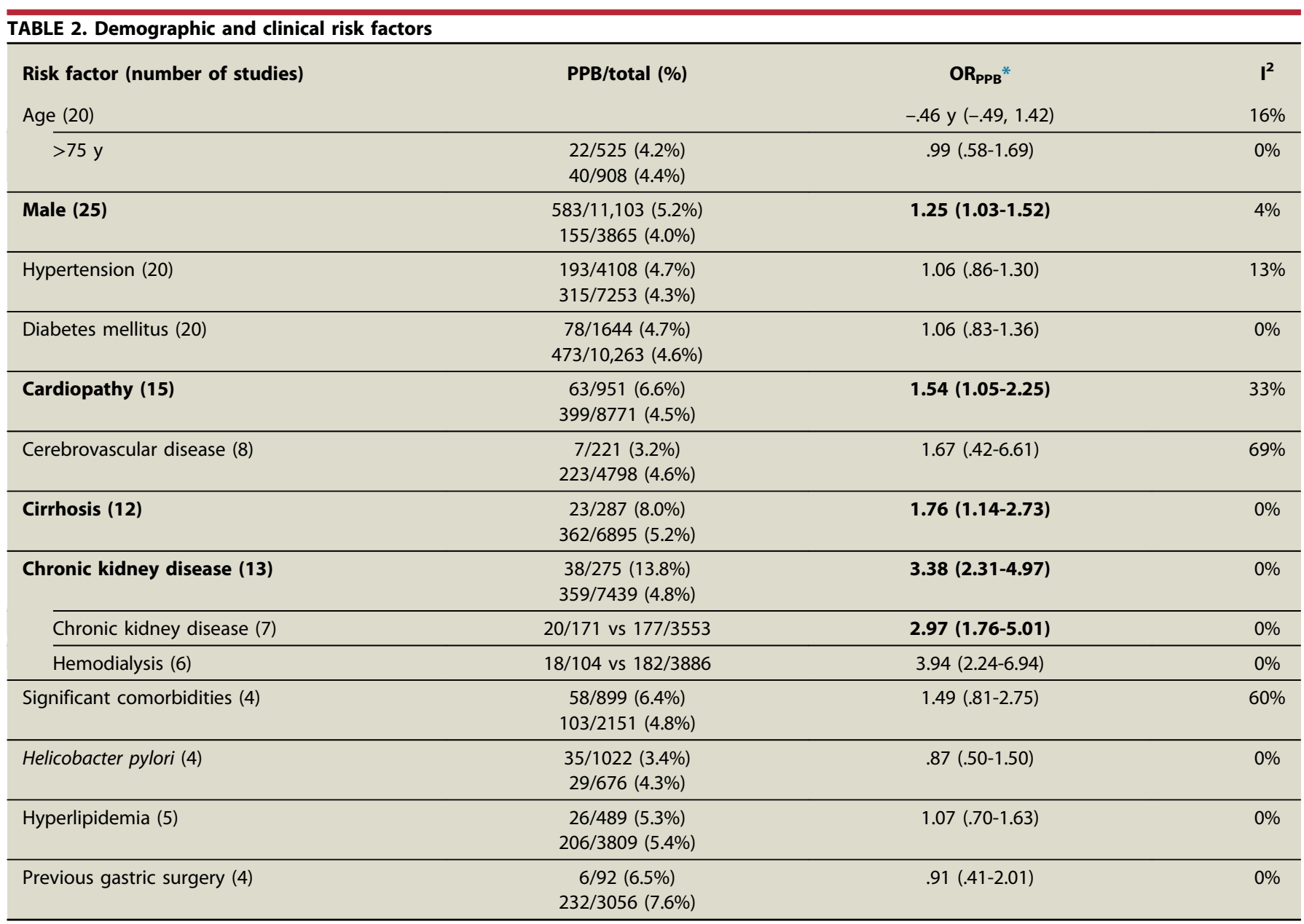

Values in bold indicate significant risk factors. $P P B$, Post-procedural bleeding; $O R$, odds ratio.

*Mean difference ${ }_{\mathrm{PPB}}$ - no PPB $(95 \% \mathrm{Cl})$.

time of bleeding and tumor location, lower sites were associated with earlier bleeding in 4 studies. ${ }^{29,33,34,62}$

Macroscopic type was also explored in several studies, with most finding no relation between morphology and PPB. ${ }^{13,18,20-24,28,29,32,34,39,42,43,61}$ However, flat, ${ }^{58}$ depressed, $^{16}$ and flat/depressed ${ }^{14,17}$ lesions were associated with increased PPB in some studies.

Most studies did not find significant differences in PPB according to histology (dysplasia or carcinoma) ${ }^{15,18,20,22,27,28,30,34,39,42}$ or invasion depth (mucosal vs submucosal), ${ }^{18,22-24,26-34,42,43}$ with few studies reporting a significantly increased risk of PPB in lesions harboring carcinoma $^{17,25}$ and submucosal invasion. ${ }^{14,36}$ Tumor differentiation $^{14,21,24,29,43}$ and lymphovascular invasion ${ }^{43}$ were not found to influence PPB. Expanded indication lesions were associated with higher PPB in 1 study, ${ }^{63}$ whereas PPB was not significantly different between standard and expanded indications in 3 studies despite a tendency for higher bleeding in the latter group. ${ }^{48,64,65}$

Ulceration was not associated with PPB, ${ }^{14,17,18,22,24,26,28-}$ $31,33,34,37-39,43,58,65,66$ except in 1 study. $^{27}$ Submucosal fibrosis has also been analyzed and was not identified as an independent risk factor. ${ }^{13,14,61,67}$ The presence of scarring was not identified as an influence on PPB in 3 studies, ${ }^{32,51,58}$ although it was associated with higher PPB in 2 studies. ${ }^{36,59}$

After meta-analysis, increased tumor and specimen size, flat/depressed morphology (Fig. 4), localization in the lesser curvature, ulceration, carcinoma histology, and expanded indication were identified as significant risk factors for PPB (Table 3). On the other hand, vertical localization was not found to influence overall PPB, although localization in the upper third was significantly associated with PPB in the group of studies that only reported the frequency of delayed bleeding (Fig. 5). Submucosal invasion and fibrosis/scarring were not found to influence PPB despite a tendency for higher bleeding in the latter situation. Concerning EMR, 3 studies did not identify size and location, ${ }^{55}$ indication, ${ }^{64}$ or ulceration ${ }^{66}$ as risk factors for PPB and were not included in the meta-analysis.

Procedural details. Poor control of bleeding ${ }^{18}$ and snaring as the final step of $\mathrm{ESD}^{68}$ were associated with 


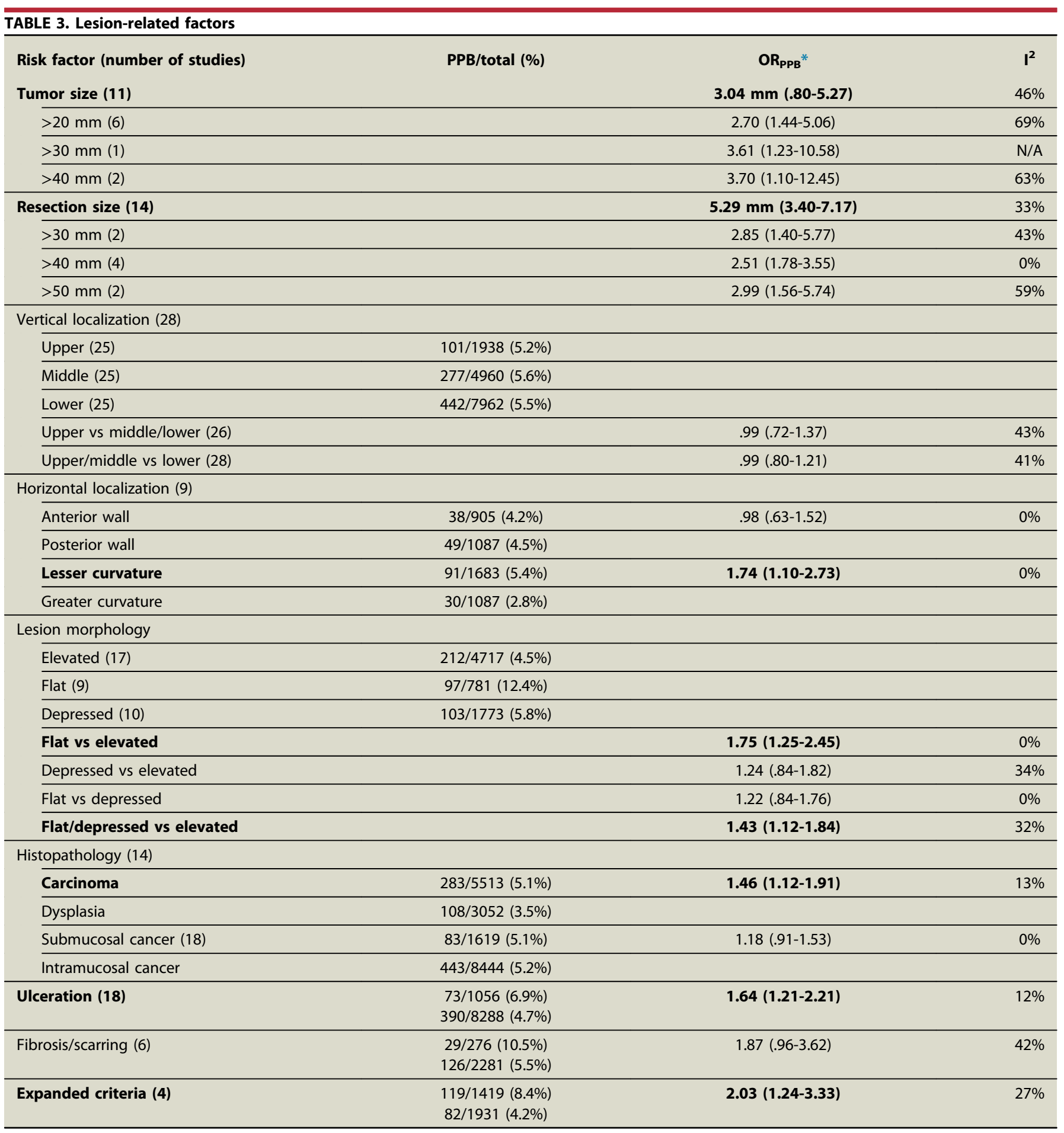

Values in bold indicate significant risk factors. $P P B$, Post-procedural bleeding; $O R$, odds ratio. ${ }^{*}$ Mean difference $\mathrm{PPB}$ - no PPB $(95 \% \mathrm{Cl})$.

increased PPB. Piecemeal resection, although not associated with higher PPB in most studies, ${ }^{13,14,17,20,22,34,42,61}$ was associated with an increased but not statistically significant risk of bleeding (Table 4).

Additional preventive measures to reduce PPB with mucosal closure with snare and $\operatorname{clips}^{69}$ or selective artery clipping ${ }^{70}$ did not decrease PPB, but coagulation of visible vessels ${ }^{31,71}$ and use of polyglycolic acid sheets and fibrin glue ${ }^{72}$ were associated with lower PPB rates (only in high-risk patients in the latter study). Vascularization of lesions evaluated by EUS, ${ }^{73}$ early diet resumption, ${ }^{74}$ and outpatient management 


\begin{tabular}{|c|c|c|c|}
\hline $\begin{array}{l}\text { Risk factor (number } \\
\text { of studies) }\end{array}$ & PPB/total (\%) & $\mathrm{OR}_{\mathrm{PPB}}{ }^{*}$ & $I^{2}$ \\
\hline Piecemeal resection (9) & $\begin{array}{c}14 / 226(6.2 \%) \\
188 / 4234(4.4 \%)\end{array}$ & $1.78(.89-3.55)$ & $25 \%$ \\
\hline $\begin{array}{l}\text { Procedure duration } \\
\text { (10) }\end{array}$ & & $6.73 \min (2.89-10.56)$ & $4 \%$ \\
\hline$>60 \min (3)$ & $\begin{array}{c}41 / 605(6.8 \%) \\
50 / 1447(3.4 \%)\end{array}$ & $2.05(1.19-3.55)$ & $25 \%$ \\
\hline \multicolumn{4}{|l|}{ Preprocedural PPI (4) } \\
\hline Preprocedural PPI & $\begin{array}{c}2 / 208(.96 \%) \\
4 / 198(2.02 \%)\end{array}$ & $.70(.14-3.53)$ & $4 \%$ \\
\hline \multicolumn{4}{|l|}{$\mathrm{H}_{2} \mathrm{RA}$ vs PPI (6) } \\
\hline $\mathrm{H}_{2} \mathrm{RA}$ & $\begin{array}{l}44 / 757(5.8 \%) \\
17 / 481(3.5 \%)\end{array}$ & $2.13(1.21-3.74)$ & $0 \%$ \\
\hline \multicolumn{4}{|l|}{ Experience (5) } \\
\hline$<50(4)$ & $\begin{array}{l}100 / 1786(5.6 \%) \\
127 / 2534(5.0 \%)\end{array}$ & $.99(.75-1.33)$ & $0 \%$ \\
\hline$<100(3)$ & $\begin{array}{c}118 / 1909(6.2 \%) \\
44 / 858(5.1 \%)\end{array}$ & $1.12(.77-1.63)$ & $0 \%$ \\
\hline \multicolumn{4}{|l|}{ SLE (7) } \\
\hline SLE & $59 / 1349(4.4 \%)$ & $1.34(.85-2.12)$ & $0 \%$ \\
\hline No SLE & $41 / 1369(2.9 \%)$ & & \\
\hline $\mathrm{RCT}(3)$ & & $1.22(.58-2.57)$ & $11 \%$ \\
\hline Retrospective (4) & & $1.45(.79-2.65)$ & $0 \%$ \\
\hline
\end{tabular}

Values in bold indicate significant risk factors.

$P P B$, Post-procedural bleeding; $O R$, odds ratio; $P P I$, proton pump inhibitor; $\mathrm{H}_{2} R A$ histamine-2 receptor antagonist; $S L E$, second-look endoscopy; $R C T$, randomized controlled trial.

${ }^{*}$ Mean difference $\mathrm{PPB}$ - no PPB $(95 \% \mathrm{Cl})$.

in low-risk patients ${ }^{75}$ were also not found to influence PPB.

Most studies found no significant differences in procedure duration between those with and without PPB. ${ }^{16,20,21,23,24,27-31,33}$ However, procedure length greater than 75 minutes, ${ }^{18} 90$ minutes, ${ }^{26} 4$ hours, ${ }^{36}$ and 5 hours $^{76}$ was associated with increased PPB in some studies. In our meta-analysis (Table 4), procedure duration was significantly higher in patients with $\mathrm{PPB}$ and duration $>60$ minutes was significantly associated with PPB.

Medications (PPIs, $\mathbf{H}_{2}$ RAs, and mucoprotectives). Pretreatment with PPIs before ESD was not associated with PPB reduction ${ }^{11,77-79}$ as well as ecabet sodium added to PPIs. ${ }^{62}$ Bolus PPI injection for 3 days yielded similar PPB rates when compared with 72 hours' perfusion in an RCT. ${ }^{14}$

With regard to the direct comparison between PPIs and $\mathrm{H}_{2}$ RAs, no significant differences in PPB were reported in 3 $\mathrm{RCTs}^{32,59,80}$ and in a retrospective study, ${ }^{20}$ whereas PPB was significantly lower in the PPI group in 2 studies. $^{60,81}$ In our meta-analysis, $\mathrm{H}_{2}$ RAs were associated with a significantly increased PPB risk.

Operator experience and fatigue. Seven studies found no differences in PPB according to operator experience, ${ }^{17,18,31,36,42,61,82}$ with only 1 study reporting significant differences in PPB between beginner ( $<50$ ESD) and experienced (>200 ESD) operators. ${ }^{33}$ Meta-analysis found that experience is not significantly associated with PPB (Table 4). Regarding fatigue, ESD workload $>2$ hours (but not prior other activities) was identified as a significant risk factor for early bleeding in a single study. ${ }^{8}$

Second-look endoscopy. SLE was not performed or not reported in 30 studies, whereas SLE was routinely performed after ESD in 34 studies (mostly on the first or second day). Seven studies directly compared PPB rates in patients with and without SLE (3 RCTs and 4 retrospective studies). ${ }^{20,22,26,30,34,61,84}$ The PPB rate in studies that performed SLE was not significantly different from studies that did not perform or did not report the use of SLE.

The clinical usefulness of SLE was evaluated in 7 studies (Table 4). ${ }^{20,22,26,30,34,61,84}$ PPB occurred in 59 of 1349 patients who underwent SLE (4.37\%) and in 41 of 1369 patients who did not have SLE (2.99\%), with no significant differences in the meta-analysis. Fourteen studies $^{13,14,17,18,20,21,23,26,28,30,34,46,61,84}$ reported the time of bleeding in relation with SLE, and in these studies $53.3 \%$ of the bleeding episodes occurred before SLE. Prophylactic hemostasis on SLE was associated with a significantly increased risk of PPB (compared with no prophylactic hemostasis on SLE).

\section{DISCUSSION}

This systematic review and meta-analysis evaluated risk factors for PPB after endoscopic resection (EMR or ESD) for gastric superficial neoplasms. This is a noteworthy issue because the literature is controversial, and many studies are underpowered to detect small but clinically significant differences.

Previous meta-analysis reported procedure-related bleeding to occur in $4 \%$ to $9 \%$ of ESDs. ${ }^{2-4}$ In our review, bleeding after ESD occurred in 5.1\% of all procedures. We believe this is the best estimate for PPB because all studies included were selected only if a clear definition of PPB was provided and reported separately from intraprocedural bleeding.

We found that male gender, cardiopathy (and AT), cirrhosis, and chronic kidney disease were significant clinical risk factors for PPB. However, although cardiopathy was significantly associated with $\mathrm{PPB}$, this increased risk is most probably associated with the use of antithrombotics. In fact, AT was associated with an increased risk of PPB (OR, 1.76). However, the difference in PPB rates was not significant in the studies that discontinued antithrombotics 1 week before and 1 week after ESD, suggesting that this may be the optimal time of AT suspension whenever possible. Additionally, we found that continuous lowdose aspirin was not associated with a significant increase in PPB in most studies. 


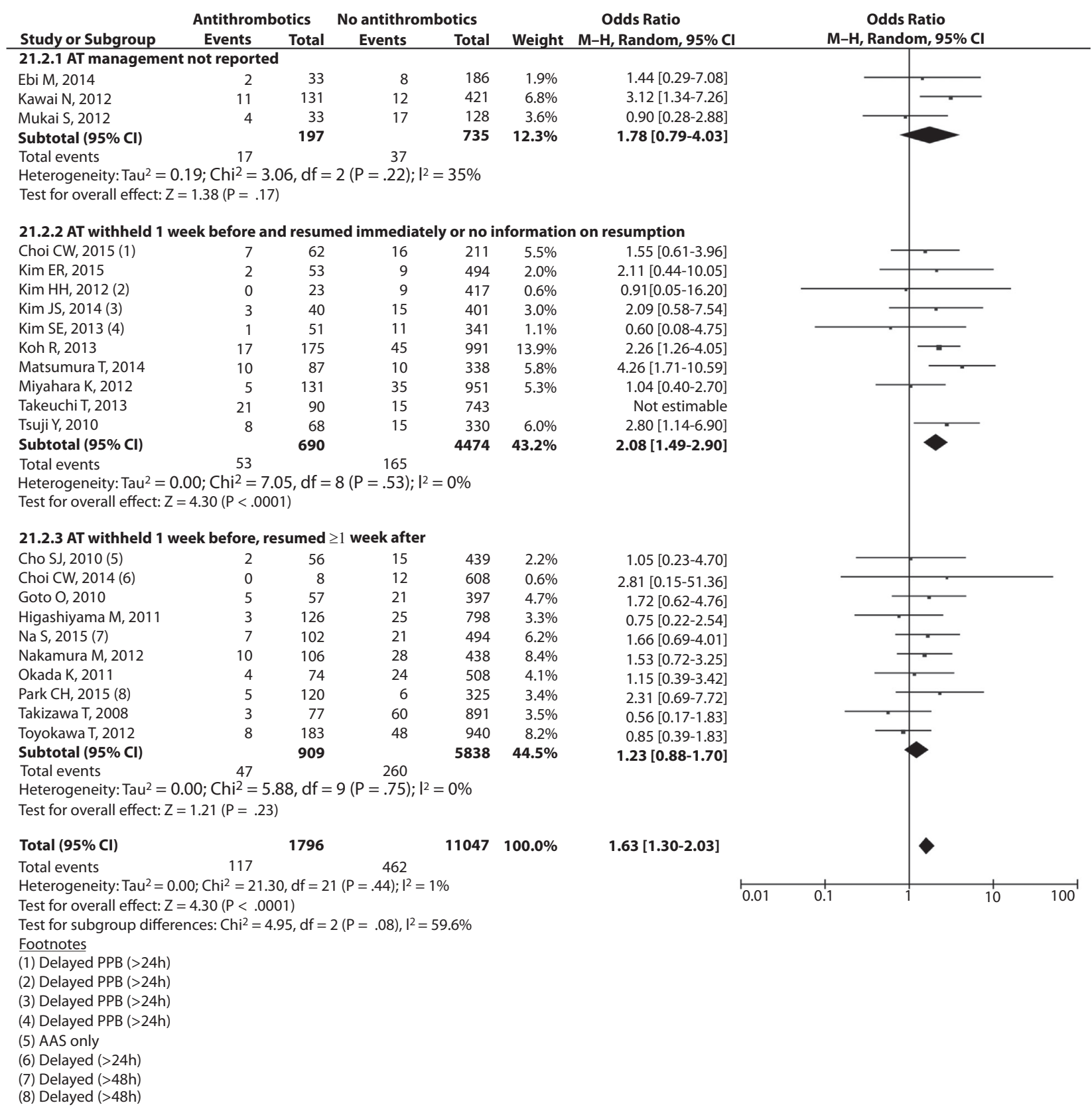

Figure 3. Forrest plot of $\mathrm{PPB}$ rate according to antithrombotic medication. Antithrombotic medication was associated with a significantly increased risk of PPB (pooled OR, 1.63; 95\% CI, 1.30-2.03; $\mathrm{I}^{2}=1 \%$ ). On subgroup analysis, antithrombotic medication was not significantly associated with $\mathrm{PPB}$ in studies that withheld antithrombotics for 1 week before and after ESD (OR, 1.23; 95\% CI, .88-1.70; $\mathrm{I}^{2}=0 \%$ ). PPB, postprocedural bleeding.

Regarding tumor-related characteristics, tumor size $>20 \mathrm{~mm}$, resected specimen size $>30 \mathrm{~mm}$, localization in the lesser curvature, flat or depressed morphology, carcinoma histology, ulceration, and expanded criteria were associated with increased PPB. On the other hand, vertical localization was not found to affect overall PPB, but upper lesions were in fact associated with delayed bleeding.

Procedural factors also may be associated with increased risk of $\mathrm{PPB}$, namely procedure duration $>60$ minutes and the use of $\mathrm{H}_{2} \mathrm{RA}$ as antacid medication. Operator's experience was not found to influence $\mathrm{PPB}$, although high-risk lesions are typically resected by the most experienced operators. Single studies found preventive coagulation of visible vessels as a beneficial measure in reducing PPB, and 2 recent studies suggested that polyglycolic acid sheets with fibrin glue may reduce PPB after gastric and colonic ESD. ${ }^{72,85}$ However, interventions like preprocedural PPIs, mucoprotectives, and routine closure with clips or artery clipping were not found to be of benefit. Endoscopic suturing of large mucosal defects after gastric 


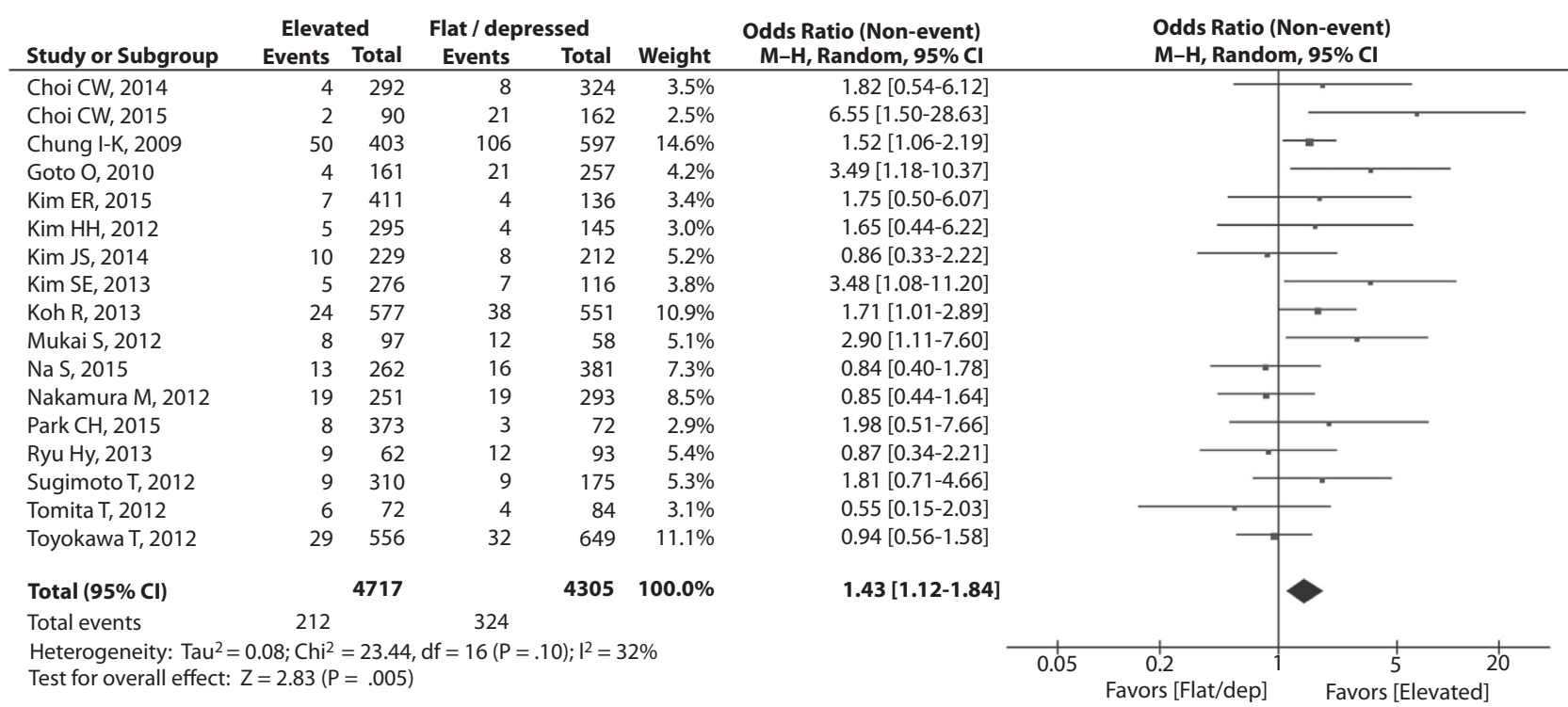

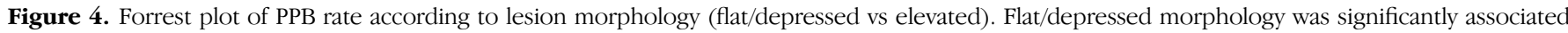
with PPB in the meta-analysis (OR, 1.43; 95\% CI, 1.12-1.84; $\mathrm{I}^{2}=32 \%$ ). PPB, post-procedural bleeding.

and colonic ESD were also reported in a single-arm study and no adverse events were seen. ${ }^{86}$ This systematic review may help in the selection of patients who are more likely to benefit from these developing techniques.

On the other hand, studies evaluating the benefit of preprocedural PPI and mucoprotectives had a low event rate and may be underpowered. Indeed, although mucoprotectives were associated with faster healing of the artificial ulcer in 2 recent reviews, ${ }^{87,88}$ its impact on PPB was not evaluated, and so it remains unclear if these faster healing decreases PPB.

SLE is routinely performed after ESD in several centers to perform hemostasis in cases of active bleeding or highrisk stigmata. Our findings clearly suggest that SLE is not associated with decreased PPB. Furthermore, more than one half of bleeding episodes occur before SLE, and even prophylactic hemostasis on SLE is not capable of reducing PPB. This suggests that even when SLE is performed, special attention should be given to patients in which prophylactic hemostasis is performed. Our findings are consistent with a recent meta-analysis limited to RCTs assessing SLE usefulness. ${ }^{89}$ Nevertheless, it remains unclear whether a subset of patients can benefit. The results were similar in retrospective studies and RCTs, although retrospective studies could have been prone to selection bias (eg, in 1 study the decision to perform SLE was made at the discretion of the endoscopist, ${ }^{30}$ and in another study the reasons to decide whether to perform SLE were not reported $\left.^{34}\right)$.

This systematic review and meta-analysis has some limitations. First, one cannot identify interactions and confounding between risk factors, although we believe that the high number of included patients and the low heterogeneity in most evaluated risk factors allow us to draw some important conclusions. Second, the different temporal definitions of early and delayed bleeding made difficult a separate analysis of risk factors for early and delayed PPB. Third, most evidence is derived from observational studies, although subgroup analysis did not find differences according to study design and most studies were judged to have low risk of bias. Fourth, some risk factors were not strictly defined in some studies and were not stratified according to disease stage (eg, ChildPugh classification in cirrhosis) and so subgroup analyses were not possible.

To our knowledge, this is the first systematic review about risk factors for PPB after endoscopic resection of early gastric neoplasms and identified the most consistently reported risk factors. As recommendations, we suggest that (1) the definition of early and delayed bleeding should be standardized (eg, considering early bleeding $<24$ hours after ESD) and (2) AT management should also be reported in detail. Based on the significant risk factors presented on Figure 2, we also suggest that early discharge can be considered in patients with 0 to 1 risk factors. For others, hospital stay may be prolonged and the role of SLE adequately assessed. Randomized trials should be performed incorporating these risk factors in randomization and addressing the role for specific interventions such as the use, duration, and dosage of PPIs; SLE, and follow-up aiming at reducing the odds for bleeding.

In conclusion, we have identified risk factors associated with PPB after ESD that can help gastroenterologists to identify patients at increased risk. It is our hope that this can guide management, namely in terms of the adequate period of surveillance after endoscopic resection. 


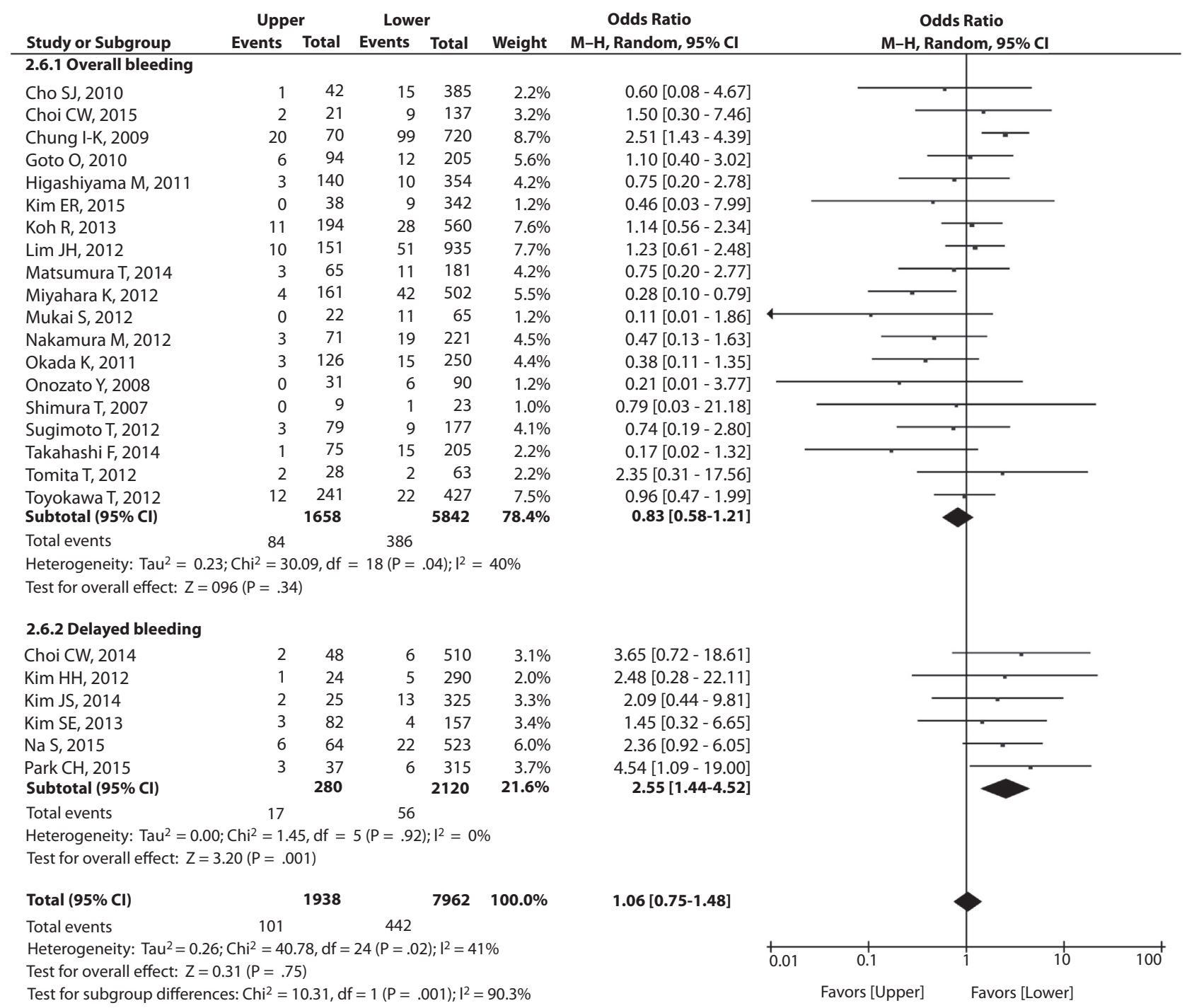

Figure 5. Forrest plot of $\mathrm{PPB}$ rate according to localization (upper vs lower). Localization of the lesion in upper or lower thirds of the stomach was not found to influence PPB $\left(\mathrm{OR}_{\text {upper localization }}=1.06 ; 95 \% \mathrm{CI}, .75-1.48 ; \mathrm{I}^{2}=41 \%\right)$. However, in subgroup analysis upper localization was significantly associated with PPB when only studies reporting delayed bleeding were considered (OR, 2.55; 95\% CI, 1.44-4.52; $\mathrm{I}^{2}=0 \%$ ). PPB, post-procedural bleeding.

\section{ACKNOWLEDGMENTS}

We thank Dr Teresa Pinto-Pais for her contribution in revising this manuscript.

\section{REFERENCES}

1. Pimentel-Nunes $P$, Dinis-Ribeiro $M$, Ponchon $T$, et al. Endoscopic submucosal dissection: European Society of Gastrointestinal Endoscopy (ESGE) Guideline. Endoscopy 2015;47:829-54.

2. Park YM, Cho E, Kang HY, et al. The effectiveness and safety of endoscopic submucosal dissection compared with endoscopic mucosal resection for early gastric cancer: a systematic review and metaanalysis. Surg Endosc 2011;25:2666-77.

3. Facciorusso A, Antonino M, Di Maso M, et al. Endoscopic submucosal dissection vs endoscopic mucosal resection for early gastric cancer: a meta-analysis. World J Gastrointest Endosc 2014;6:555-63.
4. Lian J, Chen S, Zhang Y, et al. A meta-analysis of endoscopic submucosal dissection and EMR for early gastric cancer. Gastrointest Endosc 2012;76:763-70.

5. Higgins JP, Altman DG, Gotzsche PC, et al. The Cochrane Collaboration's tool for assessing risk of bias in randomised trials. BM 2011;343:d5928.

6. Wells G, Shea B, O'Connell D, et al. The Newcastle-Ottawa Scale (NOS) for assessing the quality of nonrandomised studies in metaanalyses; 2013. Available at: http://www.ohri.ca/programs/clinical epidemiology/oxford.asp. Accessed November 2, 2015.

7. Wallace BC, Dahabreh IJ, Trikalinos TA, et al. Closing the gap between methodologists and end-users: R as a computational Back-end. J Stat Softw 2012;49:5.

8. Review manager (RevMan) [computer program], version 5.3; 2014. Copenhagen, Denmark: The Nordic Cochrane Centre, The Cochrane Collaboration.

9. Hozo SP, Djulbegovic B, Hozo I. Estimating the mean and variance from the median, range, and the size of a sample. BMC Med Res Methodol 2005;5:13. 
10. Moher D, Liberati A, Tetzlaff J, et al. Preferred reporting items for systematic reviews and meta-analyses: the PRISMA statement. Ann Intern Med 2009;151:264-9.

11. Ono S, Kato M, Ono $Y$, et al. Effects of preoperative administration of omeprazole on bleeding after endoscopic submucosal dissection: a prospective randomized controlled trial. Endoscopy 2009;41:299-303.

12. Ono S, Fujishiro M, Yoshida N, et al. Thienopyridine derivatives as risk factors for bleeding following high risk endoscopic treatments: Safe Treatment on Antiplatelets (STRAP) study. Endoscopy 2015;47:632-7.

13. Choi CW, Kim HW, Kang DH, et al. Clinical outcomes of second-look endoscopy after gastric endoscopic submucosal dissection: predictive factors with high risks of bleeding. Surg Endosc 2014;28:2213-20.

14. Choi CW, Kang DH, Kim HW, et al. High dose proton pump inhibitor infusion versus bolus injection for the prevention of bleeding after endoscopic submucosal dissection: prospective randomized controlled study. Dig Dis Sci 2015;60:2088-96.

15. Cho SJ, Choi IJ, Kim CG, et al. Aspirin use and bleeding risk after endoscopic submucosal dissection in patients with gastric neoplasms. Endoscopy 2012;44:114-21.

16. Ebi M, Shimura T, Nishiwaki H, et al. Management of systolic blood pressure after endoscopic submucosal dissection is crucial for prevention of post-ESD gastric bleeding. Eur J Gastroenterol Hepatol 2014;26:504-9.

17. Goto O, Fujishiro M, Kodashima S, et al. A second-look endoscopy after endoscopic submucosal dissection for gastric epithelial neoplasm may be unnecessary: a retrospective analysis of postendoscopic submucosal dissection bleeding. Gastrointest Endosc 2010;71:241-8.

18. Higashiyama M, Oka S, Tanaka S, et al. Risk factors for bleeding after endoscopic submucosal dissection of gastric epithelial neoplasm. Dig Endosc 2011;23:290-5.

19. Isomoto H, Ohnita K, Yamaguchi N, et al. Clinical outcomes of endoscopic submucosal dissection in elderly patients with early gastric cancer. Eur J Gastroenterol Hepatol 2010;22:311-7.

20. Kim ER, Kim JH, Kang KJ, et al. Is a second-look endoscopy necessary after endoscopic submucosal dissection for gastric neoplasm? Gut Liver 2015;9:52-8.

21. Kim HH, Park SJ, Park MI, et al. Clinical impact of second-look endoscopy after endoscopic submucosal dissection of gastric neoplasms. Gut Liver 2012;6:316-20.

22. Kim JS, Chung MW, Chung CY, et al. The need for second-look endoscopy to prevent delayed bleeding after endoscopic submucosal dissection for gastric neoplasms: a prospective randomized trial. Gut Liver 2014;8:480-6.

23. Kim SE, Kim HH, Kim JH, et al. The role of second-look endoscopy in endoscopic submucosal dissection for early gastric cancer. Turk J Gastroenterol 2013;24:218-23.

24. Koh R, Hirasawa K, Yahara S, et al. Antithrombotic drugs are risk factors for delayed postoperative bleeding after endoscopic submucosal dissection for gastric neoplasms. Gastrointest Endosc 2013;78:476-83.

25. Lim JH, Kim SG, Kim JW, et al. Do antiplatelets increase the risk of bleeding after endoscopic submucosal dissection of gastric neoplasms? Gastrointest Endosc 2012;75:719-27.

26. Matsumura T, Arai M, Maruoka D, et al. Risk factors for early and delayed post-operative bleeding after endoscopic submucosal dissection of gastric neoplasms, including patients with continued use of antithrombotic agents. BMC Gastroenterol 2014;14:172.

27. Mukai S, Cho S, Kotachi T, et al. Analysis of delayed bleeding after endoscopic submucosal dissection for gastric epithelial neoplasms. Gastroenterol Res Pract 2012;2012:875323.

28. Na S, Ahn JY, Choi KD, et al. Delayed bleeding rate according to the Forrest classification in second-look endoscopy after endoscopic submucosal dissection. Dig Dis Sci 2015;60:3108-17.

29. Okada K, Yamamoto Y, Kasuga A, et al. Risk factors for delayed bleeding after endoscopic submucosal dissection for gastric neoplasm. Surg Endosc 2011;25:98-107.

30. Park $\mathrm{CH}$, Park JC, Lee $\mathrm{H}$, et al. Second-look endoscopy after gastric endoscopic submucosal dissection for reducing delayed postoperative bleeding. Gut Liver 2015;9:43-51.
31. Takizawa K, Oda I, Gotoda T, et al. Routine coagulation of visible vessels may prevent delayed bleeding after endoscopic submucosal dissection-an analysis of risk factors. Endoscopy 2008;40:179-83.

32. Tomita T, Kim Y, Yamasaki T, et al. Prospective randomized controlled trial to compare the effects of omeprazole and famotidine in preventing delayed bleeding and promoting ulcer healing after endoscopic submucosal dissection. J Gastroenterol Hepatol 2012;27:1441-6.

33. Tsuji Y, Ohata K, Ito T, et al. Risk factors for bleeding after endoscopic submucosal dissection for gastric lesions. World J Gastroenterol 2010;16:2913-7.

34. Takahashi F, Yoshitake N, Akima T, et al. A second-look endoscopy may not reduce the bleeding after endoscopic submucosal dissection for gastric epithelial neoplasm. BMC Gastroenterol 2014;14:152.

35. Chinda D, Sasaki Y, Tatsuta T, et al. Perioperative complications of endoscopic submucosal dissection for early gastric cancer in elderly Japanese patients 75 years of age or older. Intern Med 2015;54: 267-72.

36. Miyahara K, Iwakiri R, Shimoda R, et al. Perforation and postoperative bleeding of endoscopic submucosal dissection in gastric tumors: analysis of 1190 lesions in low- and high-volume centers in Saga, Japan. Digestion 2012;86:273-80.

37. Onozato $\mathrm{Y}$, Ishihara $\mathrm{H}$, lizuka $\mathrm{H}$, et al. Endoscopic submucosal dissection for early gastric cancers and large flat adenomas. Endoscopy 2006;38:980-6.

38. Onozato $\mathrm{Y}$, Kakizaki S, Ishihara $\mathrm{H}$, et al. Feasibility of endoscopic submucosal dissection for elderly patients with early gastric cancers and adenomas. Dig Endosc 2008;20:12-6.

39. Sugimoto T, Okamoto M, Mitsuno $Y$, et al. Endoscopic submucosal dissection is an effective and safe therapy for early gastric neoplasms a multicenter feasible study. J Clin Gastroenterol 2012;46:124-9.

40. Yoshio T, Nishida T, Kawai N, et al. Gastric ESD under heparin replacement at high-risk patients of thromboembolism is technically feasible but has a high risk of delayed bleeding: Osaka University ESD Study Group. Gastroenterol Res Pract 2013;2013:365830.

41. Zhang Y, Huang L, Li L, et al. Endoscopic submucosal dissection for early gastric neoplasms in elderly patients. J Laparoendosc Adv Surg Tech A 2014;24:391-8.

42. Toyokawa $T$, Inaba $T$, Omote $S$, et al. Risk factors for perforation and delayed bleeding associated with endoscopic submucosal dissection for early gastric neoplasms: analysis of 1123 lesions. J Gastroenterol Hepatol 2012;27:907-12.

43. Nakamura M, Nishikawa J, Hamabe K, et al. Risk factors for delayed bleeding from endoscopic submucosal dissection of gastric neoplasms. Scand J Gastroenterol 2012;47:1108-14.

44. Mannen K, Tsunada S, Hara M, et al. Risk factors for complications of endoscopic submucosal dissection in gastric tumors: analysis of 478 lesions. J Gastroenterol 2010;45:30-6.

45. Kim BJ, Chang TH, Kim JJ, et al. Efficacy and safety of endoscopic submucosal dissection for early gastric cancer in patients with comorbid diseases. Gut Liver 2010;4:186-91.

46. Numata N, Oka S, Tanaka S, et al. Clinical outcomes of endoscopic submucosal dissection for early gastric cancer in patients with chronic kidney disease. J Gastroenterol Hepatol 2013;28:1632-7.

47. Man-i M, Morita Y, Fujita T, et al. Endoscopic submucosal dissection for gastric neoplasm in patients with co-morbidities categorized according to the ASA Physical Status Classification. Gastric Cancer 2013;16: 56-66.

48. Nishide N, Ono H, Kakushima N, et al. Clinical outcomes of endoscopic submucosal dissection for early gastric cancer in remnant stomach or gastric tube. Endoscopy 2012;44:577-83.

49. Lee JY, Choi IJ, Cho SJ, et al. Endoscopic submucosal dissection for metachronous tumor in the remnant stomach after distal gastrectomy. Surg Endosc 2010;24:1360-6.

50. Sanomura Y, Oka S, Tanaka S, et al. Continued use of low-dose aspirin does not increase the risk of bleeding during or after endoscopic submucosal dissection for early gastric cancer. Gastric Cancer 2014;17: 489-96. 
51. Onochi K, Jin M, Matsuhashi T, et al. Delayed bleeding after endoscopic submucosal dissection for gastric early cancer and adenoma is significantly associated with anti-coagulants agents but not with antiplatelet agents [abstract]. Gastrointest Endosc 2010;71:AB260.

52. Kawai N, Abe T, Ebara R, et al. Effects of anti-coagulation and/or antiplatelet drugs on secondary hemorrhage following endoscopic submucosal dissection in patients with gastric tumors. J Gastroenterol Hepatol 2007;22(Suppl 2):A193.

53. Kawai N, Tsumano ERI, Urabe M, et al. Synergistic effects of antithrombotic drugs on secondary hemorrhage following endoscopic submucosal dissection in patients with early gastric tumors [abstract]. Gastrointest Endosc 2012;75(Suppl 4):AB231.

54. Takeuchi T, Ota K, Harada S, et al. The postoperative bleeding rate and its risk factors in patients on antithrombotic therapy who undergo gastric endoscopic submucosal dissection. BMC Gastroenterol 2013;13:136.

55. Shimura T, Sasaki M, Kataoka H, et al. Advantages of endoscopic submucosal dissection over conventional endoscopic mucosal resection. J Gastroenterol Hepatol 2007;22:821-6.

56. Hirasaki S, Kanzaki H, Matsubara M, et al. Treatment of over $20 \mathrm{~mm}$ gastric cancer by endoscopic submucosal dissection using an insulation-tipped diathermic knife. World J Gastroenterol 2007;13:3981-4.

57. Asakuma Y, Matsui S, Kawasaki M, et al. Prevention of delayed bleeding after endoscopic submucosal dissection (ESD) for gastric tumors. Gastroenterology 2011;140:S235.

58. Chung I-K, Lee JH, Lee S-H, et al. Therapeutic outcomes in 1000 cases of endoscopic submucosal dissection for early gastric neoplasms: Korean ESD Study Group multicenter study. Gastrointest Endosc 2009;69:1228-35.

59. Uedo N, Takeuchi Y, Yamada T, et al. Effect of a proton pump inhibitor or an $\mathrm{H} 2$-receptor antagonist on prevention of bleeding from ulcer after endoscopic submucosal dissection of early gastric cancer: a prospective randomized controlled trial. Am J Gastroenterol 2007;102: 1610-6.

60. Jeong $\mathrm{HK}$, Park $\mathrm{CH}$, Jun $\mathrm{CH}$, et al. A prospective randomized trial of either famotidine or pantoprazole for the prevention of bleeding after endoscopic submucosal dissection. J Korean Med Sci 2007;22:1055-9.

61. Ryu HY, Kim JW, Kim HS, et al. Second-look endoscopy is not associated with better clinical outcomes after gastric endoscopic submucosal dissection: a prospective, randomized, clinical trial analyzed on an as-treated basis. Gastrointest Endosc 2013;78:285-94.

62. Ahn JY, Choi CH, Lee JW, et al. The effect of sequential therapy with lansoprazole and ecabet sodium in treating iatrogenic gastric ulcer after endoscopic submucosal dissection: a randomized prospective study. J Dig Dis 2015;16:75-82.

63. Yamaguchi N, Isomoto H, Fukuda $\mathrm{E}$, et al. Clinical outcomes of endoscopic submucosal dissection for early gastric cancer by indication criteria. Digestion 2009;80:173-81.

64. Ahn JY, Jung HY, Choi KD, et al. Endoscopic and oncologic outcomes after endoscopic resection for early gastric cancer: 1370 cases of absolute and extended indications. Gastrointest Endosc 2011;74:485-93.

65. Kosaka T, Endo M, Toya Y, et al. Long-term outcomes of endoscopic submucosal dissection for early gastric cancer: a single-center retrospective study. Dig Endosc 2014;26:183-91.

66. Oka S, Tanaka S, Kaneko I, et al. Advantage of endoscopic submucosal dissection compared with EMR for early gastric cancer. Gastrointest Endosc 2006;64:877-83.

67. Jeong JY, Oh YH, Yu YH, et al. Does submucosal fibrosis affect the results of endoscopic submucosal dissection of early gastric tumors? Gastrointest Endosc 2012;76:59-66.

68. Goto O, Fujishiro M, Kodashima S, et al. Feasibility of electrocautery snaring as the final step of endoscopic submucosal dissection for stomach epithelial neoplasms. Dig Liver Dis 2009;41:26-30.

69. Lee B-I, Kim B-W, Kim H-K, et al. Routine mucosal closure with a detachable snare and clips after endoscopic submucosal dissection for gastric epithelial neoplasms: a randomized controlled trial. Gut Liver 2011:5:454-9.
70. Mukai S, Cho S, Nakamura S, et al. Postprocedural combined treatment using the coagulation plus artery-selective clipping (2C) method for the prevention of delayed bleeding after ESD. Surg Endosc 2013;27: 1292-301.

71. Suzuki H, Oda I, Sekiguchi M, et al. Process of technical stabilization of gastric endoscopic submucosal dissection at the National Cancer Center in Japan. Turk J Gastroenterol 2014;25:619-23.

72. Tsuji Y, Fujishiro M, Kodashima S, et al. Polyglycolic acid sheets and fibrin glue decrease the risk of bleeding after endoscopic submucosal dissection of gastric neoplasms (with video). Gastrointest Endosc 2015;81:906-12.

73. Kikuchi D, lizuka T, Hoteya S, et al. Prospective study about the utility of endoscopic ultrasound for predicting the safety of endoscopic submucosal dissection in early gastric cancer (T-HOPE 0801). Gastroenterol Res Pract 2013;2013:329385.

74. Kim S, Cheoi KS, Lee HJ, et al. Safety and patient satisfaction of early diet after endoscopic submucosal dissection for gastric epithelial neoplasia: a prospective, randomized study. Surg Endosc 2014;28:1321-9.

75. Ahn SY, Jang SI, Lee DW, et al. Gastric endoscopic submucosal dissection is safe for day patients. Clin Endosc 2014;47:538-43.

76. Akasaka T, Nishida T, Tsutsui $\mathrm{S}$, et al. Short-term outcomes of endoscopic submucosal dissection (ESD) for early gastric neoplasm: multicenter survey by osaka university ESD study group. Dig Endosc 2011;23:73-7.

77. Baeg MK, Choi M-G, Moon SJ, et al. Preprocedural rabeprazole treatment before endoscopic submucosal dissection for gastric neoplasms. Dig Dis Sci 2014;59:2243-8.

78. Hikichi T, Sato M, Watanabe K, et al. Oral rabeprazole administration on a procedure day suppresses bleeding after endoscopic submucosal dissection for gastric neoplasms. Fukushima J Med Sci 2014;60:68-74.

79. Watanabe $Y$, Kato N, Maehata T, et al. Safer endoscopic gastric mucosal resection: preoperative proton pump inhibitor administration. J Gastroenterol Hepatol 2006;21:1675-80.

80. Imaeda H, Hosoe N, Suzuki H, et al. Effect of lansoprazole versus roxatidine on prevention of bleeding and promotion of ulcer healing after endoscopic submucosal dissection for superficial gastric neoplasia. J Gastroenterol 2011:46:1267-72.

81. Uedo N, Yamada T, Takeuchi Y, et al. Comparison of proton pump inhibitor with $\mathrm{H} 2$ receptor antagonist for prevention of bleeding from ulcer after endoscopic submucosal dissection for early gastric cancers: a non-blind randomized controlled trial [abstract]. Gastrointest Endosc 2006;63:AB98.

82. Oda I, Odagaki T, Suzuki $H$, et al. Learning curve for endoscopic submucosal dissection of early gastric cancer based on trainee experience. Dig Endosc 2012;24(Suppl 1):129-32.

83. Lim SM, Park JC, Lee H, et al. Impact of cumulative time on the clinical outcomes of endoscopic submucosal dissection in gastric neoplasm. Surg Endosc 2013;27:1397-403.

84. Mochizuki S, Uedo N, Oda I, et al. Scheduled second-look endoscopy is not recommended after endoscopic submucosal dissection for gastric neoplasms (the SAFE trial): a multicentre prospective randomised controlled non-inferiority trial. Gut 2015;64:397-405.

85. Tsuji Y, Ohata K, Gunji T, et al. Endoscopic tissue shielding method with polyglycolic acid sheets and fibrin glue to cover wounds after colorectal endoscopic submucosal dissection (with video). Gastrointest Endosc 2014;79:151-5.

86. Kantsevoy SV, Bitner M, Mitrakov AA, et al. Endoscopic suturing closure of large mucosal defects after endoscopic submucosal dissection is technically feasible, fast, and eliminates the need for hospitalization (with videos). Gastrointest Endosc 2014;79:503-7.

87. Wang J, Guo X, Ye C, et al. Efficacy and safety of proton pump inhibitors (PPIs) plus rebamipide for endoscopic submucosal dissectioninduced ulcers: a meta-analysis. Intern Med 2014;53:1243-8.

88. Nishizawa T, Suzuki H, Kanai T, et al. Proton pump inhibitor alone vs proton pump inhibitor plus mucosal protective agents for endoscopic submucosal dissection-induced ulcer: a systematic review and metaanalysis. J Clin Biochem Nutr 2015;56:85-90. 
89. Nishizawa T, Suzuki H, Kinoshita S, et al. Second-look endoscopy after endoscopic submucosal dissection for gastric neoplasms. Dig Endosc 2015;27:279-84.

Received December 14, 2015. Accepted June 7, 2016.

Current affiliations: Gastroenterology Department, Portuguese Oncology Institute of Porto, Porto, Portugal (1), Gastroenterology Department,
Centro Hospitalar de Lisboa Central, Lisbon, Portugal (2), CINTESIS (Center for Health Technology and Services Research), Faculty of Medicine, University of Porto, Porto, Portugal (3).

Reprint requests: Diogo Libânio, MD, Gastroenterology Department, Portuguese Oncology Institute of Porto, 4200-072 Porto, Portugal.

If you would like to chat with an author of this article, you may contact Dr Libânio at diogolibaniomonteiro@gmail.com.

Access to Gastrointestinal Endoscopy Online is reserved for all subscribers!

Full-text access to Gastrointestinal Endoscopy Online is available for all subscribers. ASGE MEMBER SUBSCRIBERS: To activate your individual online subscription, please visit http://www.asge.org and follow the instructions. NONMEMBER SUBSCRIBERS: To activate your individual online subscription, please visit http://www. giejournal.org and follow the prompts to activate your online access. To activate your account, you will need your subscriber account/membership number, which you can find on your mailing label (note: the number of digits in your subscriber account number varies from 6 to 10 digits). See the example below in which the subscriber account number has been circled:

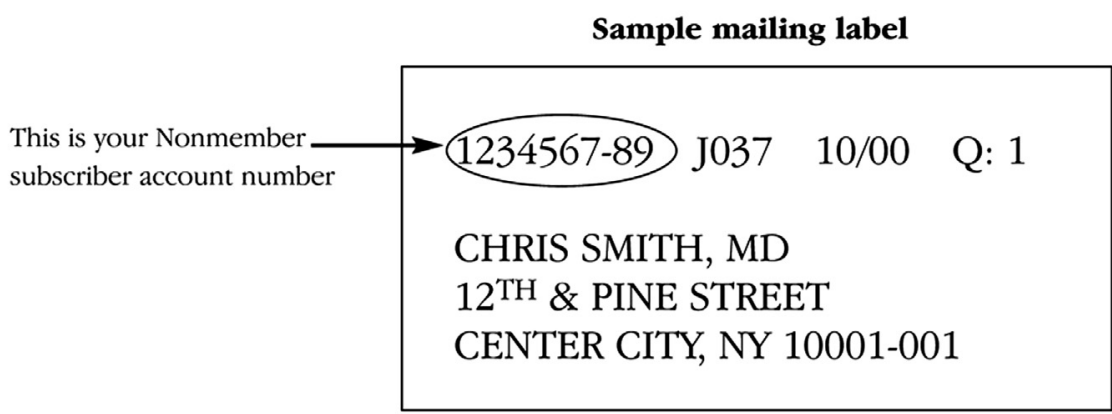

Personal subscriptions to Gastrointestinal Endoscopy Online are for individual use only and may not be transferred. Use of Gastrointestinal Endoscopy Online is subject to agreement to the terms and conditions as indicated online. 